\title{
SOBRE LA REALIDAD MITIFICADA DE CARLO LEVI*
}

\author{
Nicolás Valdés
}

"Essayons, c'est difficile de rester absolument purs.

Nous nous apercevrons alors de tout ce qui nous lie"

(Paul Eluard)

Una de las cuestiones nada ociosas del Cristo si è fermato a Eboli es a qué género se adscribe. Aunque por nuestra parte no haya ánimo de entrar aquí en polémica ${ }^{1}$, digamos de entrada que este casi ensayo (ensayo narrativo, de otro modo), al suponérsele un acercamiento casi científico a la realidad que describe, ilustra, nos parece, mejor que las novelas del período neorrealista, cuán difícil le resulta al creador ceñirse a esas dos grandes coordenadas teóricas del movimiento: la oralidad y el compromiso².

Pocas obras literarias de los años '40 tuvieron la resonancia de la del pintor y escritor turinés C. Levi. Aunque su labor cuajó en un primer ensayo Paura della libertà y en el posterior L'orologio, y en variados libros de viaje, ha sido considerado como autor de una sola obra ${ }^{3}$, a la que ceñiremos nuestra atención en el presente artículo. El sugestivo título lo obtuvo Levi del particular modo de expresarse de los campesinos lucanos, como expresamente se señala en las primeras páginas:

"Noi non siamo cristiani" essi dicono "Cristo si è fermato a Eboli"...Cristo si è davvero fermato ad Eboli, dove la strada e il treno abbandonano la costa e si addentrano nelle desolate terre della Lucania. Cristo non è mai arrivato qui, nè vi è arrivato il

\footnotetext{
* El presente artículo es una reelaboración de la conferencia pronunciada en la Universidad de Sevilla el viernes 17 de septiembre de 1993 dentro del Seminario "Narrativa italiana del s. XX: los límites del realismo".

1 M. Aurigemma -en G. Grana ed., Il Novecento. Gli Scrittori e la cultura letteraria nella società italiana (Milano, 1982) 6463- dice: "narrazione si è detto, poichè l'autore cerca di realizzare una struttura narrativa, e questa è, anche nelle intenzioni dell'autore, quanto più possibile suggestiva e mossa". Pero la difícil delimitación del Cristo se plantea también de entrada en el inteligente trabajo de M. Nieves Muñiz -"Il messaggio letterario di Cristo si è fermato a Eboli" en Critica Letteraria, n. 46 (1985, 57-70)- que se refiere a la perplejidad suscitada cuando vio la luz, y, todavía, vigente; para lo último, las palabras de Luperini: "E un romanzo? uno scritto sociologico o etnologico? un diario? Probabilmente tutte queste cose insieme."

2 Cfr. Bersani-Braschi, Viaggio nel "900 (Milano, 1984) 826-8.

${ }^{3}$ Cfr. M. Miccinesi, Invito alla lettura di Carlo Levi ( Milano, 1973-1977) 133 y sgts.
} 
tempo, nè l'anima individuale, nè la speranza, nè il legame tra le cause e gli effetti, la ragione e la Storia"4.

Como Pavese y otros intelectuales, Levi, decidido militante antifascista, conoció el destierro al desolado Sur italiano entre 1935 y 1936. A grandes rasgos, su obra no es sino el relato de su experiencia en medio de las gentes humilladas y ofendidas de Lucania, el descubrimiento de su cultura atávica, resignada e inmóvil. La cita de arriba es reveladora de las señas de identidad del Cristo, comprometido, por un lado, en una denuncia que lo aproxima al ensayo, pero, por otro, dominado por la intuición, la psicología, la impronta memorialista. Hay algo fundamental que, en nuestra opinión, cualquier exégesis de la obra debe afrontar: nos hallamos ante una percepción de la realidad cerrada, en una dimensión espacio-temporal cerrada sin fisuras.

Y hablamos, en consecuencia, de mitificación de las personas y objetos del relato porque Levi los sublima en su inmovilidad, en la esfera de su apartamiento de la historia. Ya en Paura della libertà, fechada en 1939 pero publicada en 1946, había analizado la crisis europea, poniendo el acento en un presente y futuro sin esperanza; como la obra objeto de nuestro interés, se trataba de una meditación personalísima, adscribible con dificultad en el rigor lógico del ensayo. Si en puertas de la guerra, Levi había hecho esta aportación a la literatura europea de la crisis, es fácil concebir que tres años más tarde (parece ser del '41 la redacción de la obra), en plena conflagración, en el encuentro - a través de la sugestión de la memoria - con las costumbres milenarias de Lucania, hallase un claro antídoto a la desolación de la civilización occidental.

Hablamos, por otro lado, de mitificación de la realidad leviana entendiendo el mito tal como lo entiende Barthes: no ya algo ajeno a la realidad sino simplemente una construcción irracional que la transforma y la deforma ${ }^{5}$. Es esto algo comúnmente sabido pero no por ello menos ignorado. De suerte que en el Cristo realidad y mito no son mundos enfrentados $\mathrm{y}$, en consecuencia, la descripción mitificadora de Levi no supone merma alguna en el compromiso (encaja así en los parámetros del neorrealismo más genuino, aunque esté ausente esa otra componente decisiva que es el recurso a la oralidad, a la lengua coloquial y directa, dialectal en buena medida). El compromiso se acentúa precisamente, a nuestro entender, acentuando Levi los contornos de los tipos humanos que nos presenta, enfrentados e irreconciliables en su bondad, los campesinos, por un lado, en su maldad, los señores, por otro.

El discurso maníqueo leviano, en un clima de refugio en la memoria, entronca, a nuestro entender, con los relatos del memorialismo italiano del Ochocientos. Tómense los ejemplos más conocidos: Silvio Pellico, Ippolito Nievo o, alguien, para nosotros más familiar, como Luigi Settembrini y sus Ricordanze ${ }^{6}$. Esta literatura memorialista

\footnotetext{
${ }^{4}$ Citamos ahora y después por la edición Einaudi (Torino, 1965 ); 3.

5 En A. Elorza, suplemento Temas de nuestra época de El País, 10.VI.1993, 2.

${ }^{6}$ N. Valdés, "La literatura política en Italia durante el s. XIX; Luigi Settembrini", en El siglo XIX italiano (Actas del III Congreso Nacional de Italianistas)( Salamanca, 1988) 445-54
} 
presentaba también un mundo dual, a caballo entre el costumbrismo, la denuncia y la sátira social y política, carente de un rigor histórico dado el caldo de cultivo, dada la pasión con que se cuentan los hechos, dado el esfuerzo de estos autores por unirse a la lucha del Risorgimento, contra austríacos en el Norte, el papado en el Centro, los borbones, en el Sur. Como también en Levi, primaban entonces, pues, frente al realismo de la reflexión histórico-científica, la intuición y la confesión privada?

Así planteado, el Cristo si è fermato a Eboli, no es sino un primer exponente de un memorialismo más reciente, un subgénero donde serían encuadrables también La tregua y Se questo è un uomo del otro Levi, Primo (con más éxito editorial, sin duda, en campo español que nuestro autor).

En su obra Levi entrecruza sus diferentes vivencias de desterrado político en Lucania desplegando claras complacencias literarias a las que contribuye la presencia de una voz narradora, monocorde, sin desdoblamientos del punto de vista. La técnica del desdoblamiento es ingrediente del realismo más genuino, y del específicamente italiano, si por ejemplo nos remontamos a los cuentos decameronianos donde G. Boccaccio se vierte en sus personajes y, fundiéndose con ellos, su voz narradora se confunde y multiplica, hasta participar incluso de sus elocuentes silencios, tal como con perspicacia ha señalado Segre ${ }^{8}$.

Pues bien, son pocos los contextos del Cristo, por contra, en los que se cede directamente la palabra a los campesinos lucanos, introduciéndose rara vez lo que sería un segundo plano narrativo, abundantes, por lo demás, los momentos del discurso indirecto: cuando éste hace acto de presencia entonces sí nos hallamos ante las estructuras sintácticas de ese lenguaje hablado, ante esos vocablos dialectales, caros al neorrealismo, pero esto no es la célebre mímesis ${ }^{9}$.

Carlo Levi no se acerca al mundo lucano con voluntad de civilizarlo o de transformarlo sino para preservar el universo de sus valores originarios e incontaminados. Su exclusión de la historia es, por un lado, causa de un milenario sufrimiento, que Levi, progresista y demócrata, denuncia, pero -he aquí la gran paradoja-, por otro, se convierte, al mismo tiempo en la garantía de una humanidad íntegra, de una fuente segura de fertilidad fantástica, de una ininterrumpida relación con las fuerzas de la naturaleza. Y, al decir esto, y conectando con lo antes expuesto, se nos ocurre pensar en la pervivencia de mitos románticos, en el

7 Tiene, en efecto, poco sentido hablar de estética realista en Levi, aunque ello suponga llevar la contraria a especialistas de notable peso como G.Manacorda quien considera al Cristo si è fermato a Eboli exponente más cualificado del realismo postbélico -cfr. Storia della letteratura italiana contemporanea 1940-1975 ( Roma, 1979) 127-30.

8 Baratto,Serpieri,Segre,Nencioni,Cirese, Il testo moltiplicato.Lettura di una novella del 'Decameron', Parma, 1984, 75-85.

${ }^{9}$ Clave del neorrealismo es, en efecto, el estilo, tal como señaló Calvino en su célebre prólogo a Il sentiero dei nidi di ragno : "(...)senza la varietà dei dialetti e dei gerghi da far lievitare e impastare nella lingua letteraria, non ci sarebbe stato "neorealismo" (...) Perciò il linguaggio, lo stile, il ritmo avevano tanta importanza per noi, per questo nostro realismo che doveva essere il più possibile distante dal naturalismo" (Cfr. G. Contini, Letteratura dell' Italia unita (1861-1968), Firenze, 1971, 1008-1011). 
rousseauniano "buen salvaje"10. El intelectual piamontés, en efecto, decepcionado por la postración de los valores del mundo occidental, por un mundo sumido en el Fascismo y en la guerra ${ }^{11}$, se ampara en la verdadera y naturalista civilización del profundo Sur italiano, donde no existen rivalidades y enfrentamientos entre iguales, en la que reina una armonía universal, sólo rota por la presencia de los señores.

La contradicción de la denuncia y de la defensa fue pronto percibida por la crítica del Cristo. Al poco de ver la luz, en pleno ambiente neorrealista, el descubrimiemto de esta Lucania le otorgó el favor inmediato de los lectores; todo se ajustaba a la atmósfera del momento, de suerte que la obra suscitó no ya solo el interés de sociólogos y etnólogos sino que dio pie al nacimiento del fenómeno conocido como levismo en autores como Rocco Scotellaro o Danilo Dolci. No gustaban, sin embargo, algunas características de la obra, genéricamente definidas como decadentes. Y así, paulatinamente, se fue poniendo el acento precisamente en éstas, sobre todo en análisis más recientes, dejando sentado, por lo demás, que no es en absoluto abundante la obra crítica sobre el Cristo si è fermato a Eboli. Si nadie niega esa vertiente del decidido compromiso -es decir, que Levi se pone de parte de los que, parafraseando a Camus, padecen la historia, y no del lado de los que la hacen-, si no se niega la defensa de los humillados, se hacen sin embargo lecturas más atentas a la fuga del escritor hacia la memoria (tema fundamental del novecentismo), hacia lo arcano, hacia lo arcaico: la infancia propia y la del mundo, la mujer-madre, la mujer-reina..., sin nada del complejo del hombre primitivo descrito por otros narradores meridionales ${ }^{12}$.

Dos son los polos, pues, de la poética leviana: el compromiso y el mito de lo primitivo. Entendiendo en profundidad la complejidad de este último, pueden superarse esas lecturas del Cristo como obra limitada por el lastre de un esteticismo negativo.Y sobre todo si las páginas del Cristo se ponen al lado de las del Orologio y nos percatamos de que en esta tercera obra hallamos unas reflexiones, (carentes también de la consistencia lógica atribuible a un ensayo realista) que ponen el acento en la infancia como habitual paraíso perdido, en el mundo de los sueños y su interpretación y, por encima de todo, como revela el rótulo mismo, en esa distinción entre tiempo cronólogico y tiempo psicológico. Se descubre así de qué modo tiene Levi sus raíces en la tierra de los temas dominantes de la cultura del Novecientos (Proust, Bergson, Freud, Pirandello...) ${ }^{13}$.

10 Podría abiertamente señalarse que el topos no es ya sólo romántico sino una verdadera constante de la literatura universal; pensemos, en nuestro tiempo, en el Barón calviniano -aunque, ciertamente, en clave irónica-, remóntemonos, por otra parte, a los relatos de viaje de los ss. XIV y XV y, específicamente, de las narraciones de Indias, a partir del De Canaria boccacciano de 1341 (cfr. Vittore Branca, L'America secondo Boccaccio, en Domenica de Il Sole-24 ore, 29-XII-91),1.

11 C. Muscetta -Miccinesi, ed. cit, 138-9- creyó en efecto poder abordar la crítica de Levi desde una neta preocupación política, opuesta al narcisismo de que ya se había hablado antes de 1953: "Un mondo senza storia, un mondo chiuso alla Libertà e alla Ragione: nell'era tremenda del totalitarismo l'artista che insegue una razionale Utopia libertaria non può non essere attratto dalla Civiltà delle Tenebre".

12 Cfr. A. Asor-Rosa, "Cristo si è fermato a Eboli", en L. Caretti-G. Tellini eds., Testi del novecento letterario italiano (Varese, 1990) 1136-9.

13 Esto parece pensar -contradictoriamente, según lo ya indicado: cfr. supra. n.8- G.Manacorda que subraya en Levi la "stessa necessità di una candida e sfacciata ostentazione dell'io" ; op. cit. 127. 
Pero el Cristo posee unas claves literarias bien precisas que pretendemos pasar ahora a abordar.

\section{El prólogo y el epílogo.}

Tal y como señaló en su día Matías Moreno García ${ }^{14}$ al hablar de la circularidad narrativa del principio y del final de la obra, se observan la repetición de unos esquemas retóricos que testimonian su impronta de exquisita literaridad.

Bien conocida es la transcendencia que la retórica clásica atribuye a esos espacios de la obra que son los prólogos y epílogos (implicit/ explicit ) considerándolos una especie de marcos, con un valor autónomo en la narración. De sobra se sabe que muchas veces tienen un significado fundamentalmente metaliterario, es decir que bajo el velo retórico de los topoi, permiten que nos acerquemos a la intencionalidad, al destinatario de la obra, a sus claves artísticas, en suma. Ocurría así en los textos de los tres grandes trecentistas italianos, y ocurría, de igual modo, en las versiones de nuestros traductores castellanos tardomedievales, quienes conferían a la introducción y conclusión de su trabajo una especial personalidad textual al convertirlos en espacios donde se explayaban sobre el método e intención de sus versiones, en lo que es desde luego una verdadera antesala de la teoría de la traducción, tan en boga en nuestro tiempo ${ }^{15}$.

Paréntesis cerrado, subrayemos la importancia que les otorga también Levi al extender los conceptos y términos del prólogo al epílogo de modo circular, como ya se ha dicho, dentro del espacio narrativo; y ello es metáfora de la cerrazón, del olvido, de la idiosincrasia especial del mundo arcaico descrito: de que nos hallamos en una isla en el espacio y en el tiempo tal como explítamente se señala ${ }^{16}$. Funcionando como metáfora, pues, introducción y conclusión dan coherencia a las argumentaciones y reflexiones levianas, que se insertan así en un engranaje literario-fantástico.

En las páginas iniciales Levi nos habla de su promesa a los campesinos lucanos de volver algún día a Gagliano, el lugar central del destierro. En una primera meditación nos presenta esa "nera civiltà", alejada de los caminos del progreso, encerrada en sus ritos y tradiciones, eternamente inmóvil:

"Chiuso in una stanza in un mondo chiuso, mi è grato di riandare con la memoria a quell'altro mondo, serrato nel dolore e negli usi, negato alla Storia e allo Stato, eternamente paziente; a quella mia terra senza conforto e dolcezza dove il contadino vive, nella miseria e nella lontananza, la sua immobile civiltà su un suolo arido, nella presenza della morte"17

\footnotetext{
14 Tempo e spazio in "Cristo si fermò ad Eboli" ( Salerno, 1986)18-22.

15 P.Russel, Traducciones y traductores en la Península Ibérica, 1400-1550, (Barcelona, 1985), passim.

16 "Volevo riconoscere i miei confini, che erano strettamente quelli dell'abitato: fare un primo viaggio di circumnavigazione della mia isola"(ed. cit. 35).

17 Ibidem, 3.
} 
Vemos así ya los esquemas de la dialéctica leviana: Historia-Antistoria,temporalidadatemporalidad, indivuo-colectividad, que hacen del mundo de los campesinos un territorio donde se vive lo que podríamos calificar como infancia de la humanidad ("Dove l'uomo non si distingue dal suo sole, dalla sua bestia, dalla sua malaria"18).Y surge una atmósfera misteriosa y ambigua donde la vida adquiere una doble naturaleza: la de la realidad y la de la fantasía, la de las tradiciones orales transmitidas de generación en generación, de las que el autor-narrador participa complacientemente.

Hemos hablado de cerrazón espacio-temporal textual en relación con la de la misma cultura milenaria que se nos describe, tal como el epílogo documenta. Al abandonar la tierra lucana, Levi, que cree salir de una pesadilla, del aislamiento de la historia, se percata de la imposibilidad de hacerlo racionalmente:

"Salii alla catedrale di Ancona, e mi affacciai per la prima volta dopo tanto tempo sul mare (...) Pensavo a cose vaghe: la vita di quel mare era come le sorti infinite degli uomini, eternamente ferme in onde uguali, mosse in un tempo senza mutamento. E pensai con affettuosa angoscia a quel tempo immobile, e a quella nera civiltà che avevo abbandonato" 19 .

Quedémonos con el esquema "nera civiltà", que en palabras de M. Moreno, se une a la "terra oscura" del prólogo, dado que "Inizio e fine si toccano, prologo e epilogo formano la cornice di un libro contrassegnato (perchè nato da una specifica situazione: il confino) e omogeneo nel suo insieme, malgrado la diversità delle situazioni che vi si presentano"20.

Quedémonos también con esa especie de oxímoron, affettuosa angoscia, de la precedente cita, puesto que ilustra, en el cierre, la ambivalencia -o la contradicción, según se quiera- del autor ante la realidad lucana, vista bien como refugio, bien como denuncia.

\section{La esfera atemporal.}

Proliferan por doquier, como se ha señalado arriba, las pinceladas que aluden a esa cerrazón espacio-temporal ya anticipada en el prólogo. Sobre esta base -sobre todo contando con la raya de separación espacial establecida por el mismo título Cristo si è fermato a Eboli -, a partir, pues, de la chiusura, Levi construye por categorías absolutas, privativas, el edificio de la obra; son unas dicotomías especulares (tiempo- no tiempo, individuoscolectividad indiferenciada, historia-ahistoria...) que afectan a toda la realidad analizada, que nos la traducen en clave mítica al no admitirse grados intermedios, matices, al extremarse también los perfiles de los personajes.

Hay, obviamente, una simbiosis entre las categorías negadoras. El espacio cerrado que condena a los campesinos de Gagliano a seres indiferenciados, les arrastra temporalmente en

\footnotetext{
$18 \mathrm{Ib} ., 68-9$.

$19 \mathrm{Ib}, 235$.

20 Op. cit.,21.
} 
una sucesión sin tregua de días siempre idénticos, en la inercia del monótono fluir de las estaciones:

"Il mondo è chiuso: gli odi e le guerre dei signori sono il solo avvenimento quotidiano"21.

"Questa Italia si è svolta nel suo silenzio, come la terra, in un susseguirsi di stagioni uguali e di uguali sventure, e quello che di esterno è passato su di lei, non ha lasciato traccia, e non conta"22.

"L'eterno ozio borbonico si estendeva sul paese costruito sulle ossa dei morti; distinguevo ogni voce, ogni rumore, ogni sussurro, come una cosa nota da tempi immemorabili, infinite volte ripetuta, e che infinite volte sarebbe ripetuta in futuro"23.

Podríamos seguir acumulando citas sobre la anulación del tiempo en la realidad lucana del Cristo porque es tema central del que derivan las demás categorías, pero ahondemos ahora en otra dicotomía fundamental.

\section{La antistoria.}

Carlo Levi concibe la historia como una relación de causas y efectos, como algo ligado al mundo burgués, a las sociedades industrializadas, con un determinado sistema económico. Recordamos nosotros una sencilla definición clásica de la historia que la presenta como la obra del hombre en el tiempo. Si en la Lucania leviana el cómputo cronológico no existe, tampoco puede interferirse racionalmente en el curso de las cosas, tampoco el campesino puede sustraerse al determinismo naturalista que le pone la muerte como una realidad presente en su vida casi cotidianamente. La consecuencia, sin embargo, de este apartamiento no puede ser otra que un estado prehistórico, dominado por la superstición, lo arcano, el mito. El italianista francés Dominique Fernández, crítico especializado en la novelística del periodo, fue rotundo al afirmar que "L'intera opera di Carlo Levi si spiega partendo dalla protesta contro l'uomo occidentale"24.

Frente a la Razón y la Religión de nuestra cultura, se nos propone, en efecto, una tierra dominada por la fantasía, por el misterio, porque "Accanto al linguaggio razionale, fatto di parole, c'è un altro linguaggio in cui Carlo Levi crede; un linguaggio irrazionale, magico, assai più efficace (...)"25. Nos hallamos, en efecto, en el Cristo inmersos en un politeismo neto, que es fuente segura de fantasía, como en las edades más remotas del ser humano:

21 Ed. cit., 20.

22 Ib. 123.

23 Ib.233.

24 D. Fernández, Uomini-dei o uomini-piante, in Galleria, fasc. 3-6 (1967) 160. Protesta pero, tal como afirma A. Asor-Rosa, sin que tengamos una "polémica progressista nel significato più comune del termine". Levi «individua nella civiltà contadina un complesso globalmente positivo di valori, che non si tratta di disintegrare e di distruggere, bensì di riconoscere e conservare» (cit. 1137).

25 Ibidem. 
"Tutto è magia naturale. Anche le cerimonie della chiesa diventano dei riti pagani, celebratori della indifferenziata esistenza delle cose, degli infiniti terrestri dèi del villaggio" 26 .

Por todo ello Fernández insiste en el lado fabulístico de la obra: "Album di immagini e anche racconti di fate. Cristo si è fermato ad Eboli è certamente il più bel racconto moderno di fate; con fate vere, stregoni e draghi; e una atmosfera magica e infantile dove i confini del reale sono aboliti"27 Ello es así puesto que en esta Lucania todo es posible, todo lo fantástico, realizable, hasta la doble naturaleza de los seres vivos, como claramente Levi nosa señala:

"Che ci fossero, da queste parti, dei draghi, nei secoli medioevali (i contadini e la Giulia, che me ne parlavano, dicevano -"In tempi lontani, più di cent'anni fa, molto prima del tempo dei briganti") non fa meraviglia: nè farebbe meraviglia se ricomparissero ancora, anche oggi, davanti all'occhio atterrito del contadino. Tutto è realmente possibile, quaggiù, dove gli antichi iddii dei pastori, il caprone e l'agnello rituale, ripercorrono, ogni giorno, le note strade e non vi è alcun limite sicuro a quello che è umano verso il mondo misterioso degli animali e dei mostri" 28

Estamos en algunos momentos ante una armonía naturalista, ingenua, idílica propia, casi diríamos, de una Edad de Oro virgiliana, donde incluso han sido abolidos los códigos morales:

"In paese ci restano molte più donne che uomini: chi siano i padri non può più avere un'importanza così gelosa: il sentimento d'onore si disgiunge da quello di paternità: il regime è matriarcale(...) Se i figli illegittimi non sono una reale vergogna per le donne, tanto meno lo sono, naturalmente, per gli uomini. I preti hanno quasi tutti dei figli, e nessuno trova che la cosa porti disdoro al loro sacerdozio..."29

Por no faltar, ni siquiera falta en este mundo arcádico de los labradores lucanos esa especie de cultura libresca característica de la literatura pastoril tradicional. Tiene lugar en Gagliano, en efecto, la representación de La fiaccola sotto il moggio , aunque, como podía esperarse, vaciado el drama dannunziano de su retoricismo estetizante:

"Rimaneva quello che avrebbe dovuto essere, e non era, l'opera di D'Annunzio, una feroce vicenda di passioni ferme, nel mondo senza tempo e senza storia"

$\mathrm{Al}$ margen de que puede perfectamente hacerse una lectura metaliteraria del presente pasaje -se verá más adelante-, digamos que hubiese sido poco menos que incomprensible, en los momentos en que Levi escribe su obra, aludir a D'Annunzio y no refutarlo. El antidannunzianismo del piamontés se manifiesta incluso en su esbozado planteamiento político de un D'Annunzio vate del fascismo opuesto a la armonía primitiva del mundo lucano y causante, al mismo tiempo, del olvido secular de éste:

\footnotetext{
26 Ed.cit. 102.

27 Art. cit, 172. Y es precisamente en la «via della elegia» donde I. Calvino ubica a Levi -"primo autore del Nord a interpretare is Sud"- cuando analiza la crisis y salidas del neorrealismo (Cfr. "Tre correnti del romanzo italiano" en Caretti-Tellini, cit.., 1134).

28 Ed. cit, 98

29 Ibidem,89-90.
} 
"In quella serata, spogliata la tragedia, dagli attori e dal pubblico, di tutto il dannunzianesimo, restava soltanto un contenuto grezzo ed elementare, che i contadini sentivano proprio. Era un'illusione, ma mostrava la verità. D'Annunzio era uno dei loro: ma era un letterato italiano e non poteva non tradirli. Egli era partito di qui, da un mondo senza espressione, e aveva voluto sovrapporgli la veste brillante della poesia contemporanea, che è tutta espressività, sensualità, senso del tempo. Aveva perciò degradato quel mondo a puro strumento retorico(...). Da quel connubio ibrido non poteva che nascere un mostro" 30 .

Resurge con fuerza, pues, el mito -romántico donde los haya- de la integridad y de la pureza de las clases populares ${ }^{31}$. Sin embargo, junto a la negativa valoración moral de D'Annunzio, nos encontramos el rechazo de su majestuosidad formal, que se juzga huera, antinatural. Es ello curioso, toda vez que, como ya se ha señalado, sobreviven en Levi tantos esquemas que, si bien no tienen una precisa filiación dannunziana, sí son claramente decadentes o tardo-románticos. Estaríamos,así las cosas, ante un choque obvio entre el Levi comprometido y la praxis del quehacer literario ${ }^{32}$. En éste, natural e inevitablemente, tenían que desembocar las lecturas y la experiencia formativa de los años juveniles, siendo así que Levi y la práctica totalidad de los narradores neorrealistas, por oposición a lo ocurrido en el campo cinematográfico (que surge ex novo, que no contaba apenas con relevantes tradiciones ${ }^{33}$ ) eludieron los principios programáticos del movimiento al apartarse de la auténtica realidad popular, es decir, al mitificarla.

Ya de vuelta al tiempo inmóvil de esta Lucania del Cristo si è fermato a Eboli, subraya la crítica más inteligente la superposición de los mitos de la infancia del mundo y la propia del autor. Con acierto, pues, se ha dicho que "Il regno immaginario di Levi, prima di essere il Sud è l'infanzia". Hay algunos fragmentos, en efecto, de L'Orologio que hablan de la dimensión eterna, atemporal, de la niñez, sobre todo para quien desde la madurez, advierte claramente el paulatino abreviarse del tiempo ${ }^{34}$, y que nos confirman el influjo de las doctrinas del psicoanálisis en nuestro autor, algo que estaba evidentemente en el clima de la época si pensamos en la obra de Cesare Pavese.

30 Ed. cit., 162

31 Asor-Rosa subraya el populismo «assolutamente incondizionato» del Cristo qu recuerda la intensidad del gran populismo narrativo ruso, utopista, del romanticismo (cit. 1137-8).

32 Ibidem. 1137. Se habla en efecto de «una forma di decadente superomismo».

33 cfr. Viaggio nel '900, cit. 826-7.

34 En L'Orologio - (Torino, 1989)14-5-, tras aludir Levi al Paraíso Terrestre como mito de la infancia y también de la eternidad, sus palabras encuentran confirmación en las siguientes de su interlocutor Martino: "Tu sai che il cuore del bambino, prima della nascita, nel ventre della madre, batte il doppio più in fretta del nostro cuore, e tuti i suoi organi e i suoi tessuti, le sue cellule sono in continua e attivissima formazione. Ogni suo momento è talmente pieno, ogni ora del suo tempo contiene una così immensa quantità di nuove creazioni, che si potrebbe dire che egli viva quasi nell'eternià. Dopo la nascita, i processi già rallentano, ma sono sempre vivacissimi: in pochi anni si cresce in modo incredibile. E si impara un'infinità di cose(...) Non siamo nell'eternità assoluta, ma ci siamo ancora molto vicini. Ce ne allontaniamo poi, a mano a mano che diventiamo uomini fatti: uomini fatti, dove c'è ben poco più da fare (...) così, poichè siamo diventati lenti, cominciamo a sentire che i81 tempo si è fatto rapido, e aguardare indietro con nostalgia". 
El fluir del tiempo constituye siempre en Levi una verdadera obsesión y, simplemente como tal resulta poco persuasivo, nos dice M. Aurigemma ${ }^{35}$. Situarse fuera del tiempo real viene a ser el recurso para los buceos interiores, las divagaciones, el refugio de la infancia. Es algo, en suma, inherente a su personalidad que se concentra sabiamente en la isla lucana pero que se presenta también como forma aderente de su gusto por un "sensible vagabundeo": en sus Poesie dell'orologio, de 1950 evoca Levi "le vicende giustapposte e senza storia" y se autodescribe "come un uccello nell'aria che imbruna/ sopra i campi violetti delle altane/ vedute ho a volo queste storie vane/ affidandomi al vento e alla fortuna"36.

\section{El antiestado}

Hablando antes de las dicotomías de la atemporalidad y de la ahistoria estábamos implicándonos naturalmente en otra, la de la negación del Estado. Así al referirnos al D'Annunzio particular de Levi se subrayó el hecho de que, como poeta italiano ${ }^{37}$, su papel no era sino traicionar a los campesinos lucanos. Y ello es así porque en el Cristo el estado italiano es rechazado de plano viéndose que ni siquiera las soflamas de la victoria en la guerra de Abisinia conmueven lo más mínimo a esta tierra humilde: se trata de una batalla de otros, comprensible sólo por un mundo de valores alejado del de los campesinos:

"Ed era come se non udissero le fanfare ottimistiche della radio, che venivano di troppo lontano, da un paese di attiva facilità e di progresso, che aveva dimenticato la morte, al punto di evocarla per scherzo, con la leggerezza di chi non ci crede"38

Cristo, el símbolo de la civilización occidental, se convierte también como consecuencia, no ya sólo en el de un bienestar fatalmente inalcanzable, sino en un mal endémico, peor que ciertas catástrofes naturales:

"Lo Stato qualunque sia, sono "quelli di Roma" e quelli di Roma, si sa, non vogliono che noi si viva da cristiani. C'è la grandine, le frane, la siccità, la malaria, e c'è lo Stato. Sono dei mali inevitabili, ci sono sempre stati e ci saranno sempre(...) Lo Stato è più lontano del cielo, e più maligno, perchè sta sempre dall'altra parte"39.

Son éstas indudablemente las pinceladas más comprometidas. El campesino no puede sino resignarse, admitiendo que no podrá jamás salir del círculo vicioso de su ignorancia y de la sumisión a un estado opresor. Su única salida, la autodefensa colectiva, el sufrimiento compartido:

\footnotetext{
35 Grana, ed. cit.,6470.

36 Ibidem.

37 Precisamente esencia del movimiento neorrealista era el descrubimiento de las otras italias, de las variedades regionales de suerte que los autores compartían una posición antirretórica, antinacionalista y, por supuesto, antifascista (Cfr. I. Calvino, Prólogo a Il sentiero dei nidi di rango, ed. 1964, cit.).

38 Ed. cit. 69.

39 Ibidem, 67.
} 
"Questa fraternità passiva, questo patire insieme, questa rassegnata, solidale, secolare pazienza è il profondo sentimento comune dei contadini, legame non religioso, ma naturale" 40

Estos hombres -"in tutti i sensi del termine pagani, non cittadini", dice Leviconstituyen una masa indiferenciada que sí apoya, por el contrario, y como reacción, otra guerra, mitificada y sentida como algo épico porque de una lucha desigual se trata:

"Ma una guerra era in cima ai cuori di tutti, e su tutte le bocche, trasformata già in leggenda, in fiaba, in racconto epico, in mito: il brigantaggio" (...)"Con il brigantaggio, la civiltà contadina difendeva la propria natura, contro quell'altra civiltà che le sta contro e che senza comprenderla, eternamente la assoggetta"41.

\section{El viaje interior}

Pero el Cristo si è fermato a Eboli, además de lo dicho, significa una especie de viaje ${ }^{42}$ iniciático, un camino purificador. Hay una lectura metafísica -paralela al análisis literalhistórico- cuyas bases, en los límites de la bibliografía que hemos consultado, fueron planteadas por Giovanni Falaschi, y después, desarrolladas por M. Nieves Muñiz, a partir del análisis del capítulo inicial. Ya C.Muscetta apuntaba la doble perspectiva con que ha de abordarse la obra: cómo es la Lucania de Levi, por un lado, y cómo es, por otro, Levi en esta Lucania ${ }^{43}$. Gracias a la memoria, el individuo diferenciado Levi reconoce haber vivido las experiencias comunes de la humanidad, que no son otras que las que le revela la masa indiferenciada de los campesinos lucanos. Hay un momento prenatal en el que todos participamos de las mismas formas de la cultura campesina; penetrar en ésta, y sim-patizar, es, en último término, reconocernos y renovarnos. Este nos parece el mensaje último de Carlo Levi, y al mismo se llega teniendo siempre en cuenta esos dos referidos planos: primero, histórico, de un Levi intelectual progresista en el clima postbélico, y luego, psicológico, fundado en la relación interna e irracional entre el narrador y protagonista y el mundo prehistórico del Sur.

El concepto, muy repetido en la poética leviana, de la "compresenza dei tempi" es decisivo asimismo para la comprensión del significado del Cristo. Se trata de la suma de varias experiencias en un único punto o, como nos dice el autor mismo, "il senso della storia che si svolge in noi e fuori di noi" 44 . Esta compresencia de tiempos nos permite, pues, entender esos dos enfoques paralelos, comprender la sintonía de Levi con los campesinos en un imaginario mítico irracional compartido.

\footnotetext{
40 Ibidem, 68

41 Ibidem, 121 y 123.

42 Para el viaje como tema dominante en Levi, cfr. Caretti-Tellini ed., Testi del Novecento letterario italiano,(Varese, 1990) 1044. En el Vittorini de Conversazione in Sicilia es por otra parte, el viaje tema central.

43 En Manacorda, cit., 127.

44 G. Falaschi-en Grana, ed. cit- 6492
} 
Pero el piamontés se erige al mismo tiempo en mediador entre la cultura burguesa y la lucana, ejerciendo de secretario de ésta (léase, poseedor de sus secretos) y, en el mismo plano, de transmisor de los mismos cuando a los del otro lado de Eboli nos permite franquear la puerta de este Sur, patria de la humanidad. Así lo señaló perspicazmente Calvino : "è il testimone della presenza d'un altro tempo all'interno del nostro tempo, è l'ambasciatore d'un altro mondo all'interno del nostro mondo (...) E allora ci prende come una vertigine d'un mondo diverso che ruota nel suo tempo diverso, in un'altra dimensione del nostro, da noi che seguiamo il tempo dei contachilometri e delle rotative dei quotidiani"45.

Una de las interpretaciones más sugerentes del lado psicológico del Cristo la ha realizado Nieves Muñiz al incidir en este momento inicial difícil del tránsito de un mundo -noto- al otro -ignoto-. Todo es perplejidad, todo se define por negación, en esta especie de descenso a los infiernos que conlleva en Levi la paulatina inversión de esquemas culturales; lo ignoto se va volviendo noto tanto para Levi como, obviamente, para el lector: "Ritrovate le radici del mito lucano il viaggiattore non scopre 'l'oscura virtù' di questa terra che come allusione al Nulla primordiale. La conseguente perdita di aureola del mistero inizialmente posto nel futuro Eldorado o lasciato alle spalle come rimpianto edenico (che sono le due facce della Sehnsucht romantica) è evidente: si tratta qui di un mito presente (...) di un simbolo che invece di alludere a un significato ulteriore rimanda tautologicamente a se stesso costringendo lo spettatore a percepire l'altrove come un qui, anzi a far coesistere le due percezioni" 46 .

Nada, pues, desde esta posición crítica, permite colocar al Cristo dentro de la estética realista ${ }^{47}$. El acceso al otro lado permite, en consecuencia, superada la dificultad primera, estar armonizando los dos tiempos, el interior del autor-narrador, y el de su descripción de la Lucania; y entendiendo -tal como lo quiso Pavese- el Mythos como enfrentado al Logos, la solución artística ideal sería la representación gestual, desnuda, simbolizada por la citada versión popular de la Fiaccola sotto il moggio, que, alejada de esa lectura literal que hicimos con anterioridad, tendría un primer valor exegético, metaliterario: "una concezione dell'arte come autonegazione in quanto rifiuto dell'espressività per arrivare attraverso un percorso fondato sull'eliminazione sistematica della forma a riprodurre sì il mondo dei contadini ma come mondo -ecco la differenza- senza espressione ", nos dice Muñiz.

\footnotetext{
45 Calvino, La compresenza dei tempi, en "Galleria" fasc. 3-6 (1967)238-9

46 Art. cit. 65.

47 El campesino no habla directamente, como ya indicamos; es el autor-narrador quien nos filtra, interpretándola, la realidad lucana representada. Son, en tal sentido, válidas las palabras de Muscetta: Mi par chiaro che la prospettiva tradizionale della letteratura in cui il Mezzogiorno è protagonista, nel libro di Levi è capovolta. In Verga, in Alvaro, in Vittorini è sempre uno della "tribù' che parla. Vittorini con i suoi astratti furori; Alvaro con la sua assorta memoria; Verga più di tutti eloquente, col silenzio della sua grave "impassibilità". Non si potrebbero citare scrittori umanamente e artisticamete più remoti dal gusto di Levi" (Caretti-Tellini, ed. cit. ,1048-9)
} 
Hablamos, consecuentemente, de la vitalidad de temas y mitos de la literatura novecentista en Levi, puesto que su poética guarda clara relación con lo que alguien ha llamado la nada anonadante de Giuseppe Ungaretti, con ese "inesprimibile Nulla", que es, al mismo tiempo, aspiración en el ser y en la escritura, de los poemas de la Allegria. La nada ontológica del mundo coexiste con la nada primigenia, pre-racional, del mundo sin palabras. Así la carta-prólogo del Cristo nos dice:

"Per questo il Cristo si è fermato a Eboli mi pare oggi il primo momento di una lunga storia, che è continuata modificandosi, e continua diversa, in me e nelle cose e nei fatti e nei cuori degli uomini, e in tutti i libri che ho scritto, e in quelli che scrivo e scriverò...fino a quando sarò capace di vivere la contemporaneità e la consistenza e l'unità di tutto il reale, e di intendere fuori della letteratura, il senso di un gesto, di un volto, e della parola, come semplice, poetica libertà".48

Subrayemos ya, concluyendo, cómo Levi, nos confirma en la difícil adherencia de los diferentes autores al neorrealismo, puesto que en el Cristo si è fermato a Eboli el plano realista de la denuncia se entrecruza con el de la confesión, el análisis psicológico, la duda interior. Plantea, por una parte, una descripción mitificadora del objeto sobre la base de esas dicotomías especulares de que hemos venido hablando, plantea, por otro y en paralelo -tautológicamente, se ha dicho-, una ostentación del yo poético a través de los habituales recursos de la huida a la infancia, de la disolución en una nada primitiva y mítica. La isla lucana no es sino un territorio nuevo que le permite revisar los valores de la civilización occidental, cuestionarla, plantearse los interrogantes últimos de la existencia. Más alla de la indudable carga sociológica, destaca en primer plano en el Cristo la emotividad, el calor con que Levi se acerca al objeto. Lo señaló, en fin, casi lapidariamente Calvino: "Questa dell'amore per le cose di cui parla è una caratteristica che bisogna tener presente se si vuole riuscire a definire la singolarità dell'operazione letteraria di Levi"49.

Puesto que hemos hablado de D'Annunzio se nos occure concluir recordándolo. Si Carlo Levi hubiese tenido que situarse ante el conocido dilema dannunziano de "la vita, o la si vive o la si scrive", creemos que, tras lo expuesto aquí, fácil resulta pensar en qué extremo del mismo lo haría.

\footnotetext{
${ }^{48}$ Ed. cit., IX. Hablamos, por otro lado, arriba de Ungaretti como podríamos en verdad haberlo hecho de casi cualquier otro poeta hermético italiano, para quien la postura de renovación estética (hay un neto desacuerdo con el miscere utile dulci horaciano de la poética tradicional) es también una renovación moral. Esta extrema reducción, este misticismo de la palabra ("poetica della parola", para Oreste Macrí) de raigambre mallarmeana, guarda relación, pues, con la postura extrema de Levi, desencantado, como los herméticos, de los valores de nuestra civilización occidental. Para el hermetismo, cfr. D. Valli, Storia degli ermetici (Brescia, 1978)

49 Calvino, cit. 239.
} 
